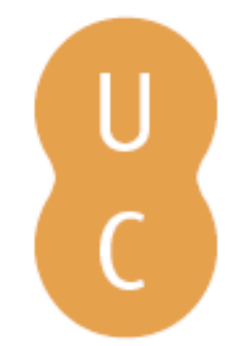

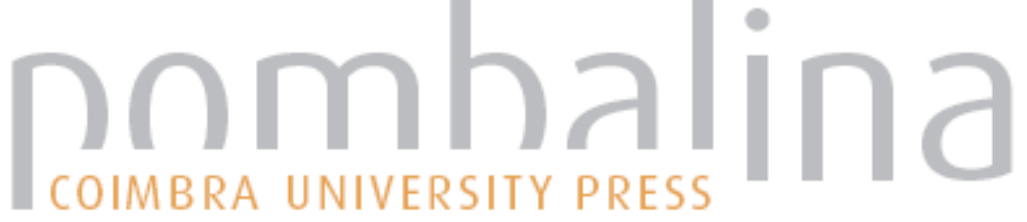

\section{Ontologia pragmática do agir em S. João de Deus}

Autor(es): $\quad$ Borges, Augusto Moutinho

Publicado por: Imprensa da Universidade de Coimbra

URL

persistente:

URI:http://hdl.handle.net/10316.2/31612

DOI:

DOI:http://dx.doi.org/10.14195/978-989-26-0199-1_17

Accessed : $\quad$ 26-Apr-2023 03:26:44

A navegação consulta e descarregamento dos títulos inseridos nas Bibliotecas Digitais UC Digitalis, UC Pombalina e UC Impactum, pressupõem a aceitação plena e sem reservas dos Termos e Condições de Uso destas Bibliotecas Digitais, disponíveis em https://digitalis.uc.pt/pt-pt/termos.

Conforme exposto nos referidos Termos e Condições de Uso, o descarregamento de títulos de acesso restrito requer uma licença válida de autorização devendo o utilizador aceder ao(s) documento(s) a partir de um endereço de IP da instituição detentora da supramencionada licença.

Ao utilizador é apenas permitido o descarregamento para uso pessoal, pelo que o emprego do(s) título(s) descarregado(s) para outro fim, designadamente comercial, carece de autorização do respetivo autor ou editor da obra.

Na medida em que todas as obras da UC Digitalis se encontram protegidas pelo Código do Direito de Autor e Direitos Conexos e demais legislação aplicável, toda a cópia, parcial ou total, deste documento, nos casos em que é legalmente admitida, deverá conter ou fazer-se acompanhar por este aviso. 
Maria Manuela Tavares Ribeiro

Coordenação

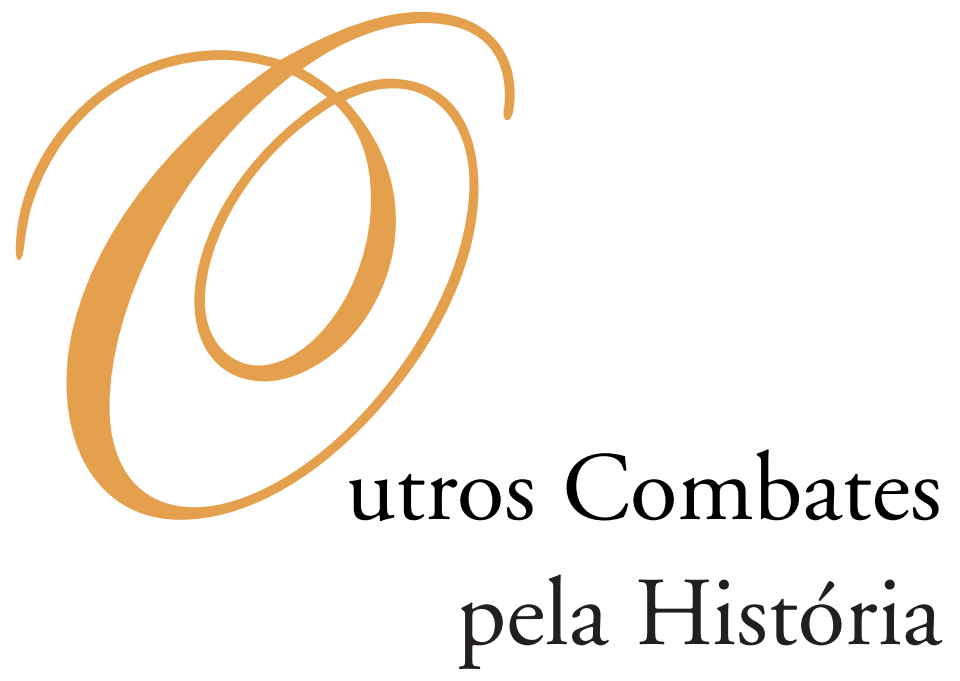




\section{COORDENAÇĀO EDITORIAL}

Imprensa da Universidade de Coimbra

Email: imprensauc@ci.uc.pt

URL: http://www.uc.pt/imprensa_uc

Vendas online: http://livrariadaimprensa.com

\section{CONCEPÇÃO GRÁFICA}

António Barros

\section{ORgANIZAÇĀO DOS TEXTOS}

Isabel Maria Luciano

Marlene Taveira

PRÉ-IMPRESSÃO

António Resende

Imprensa da Universidade de Coimbra

EXECUÇÃO GRÁFICA

SerSilito • Maia

ISBN

978-989-26-0041-3

DEPósito LEGAL

OBRA PUBLICADA COM O APOIO DE:

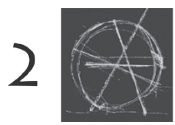

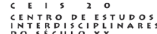

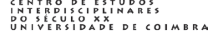

FCT Fundação para a Ciência e a Tecnologia

MINISTÉRIO DA CIÊNCIA, TECNOLOGIA E ENSINO SUPERIOR Portugal

Programa Operacional Ciência, Tecnologia, INOVAÇĀo DO QUADRo COMUNITÁRIO DE APOIO III

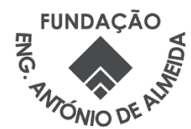

C JULHO 2010, IMPRENSA DA UNIVERSIDADE DE COIMBRA 
Maria Manuela Tavares Ribeiro

Coordenação

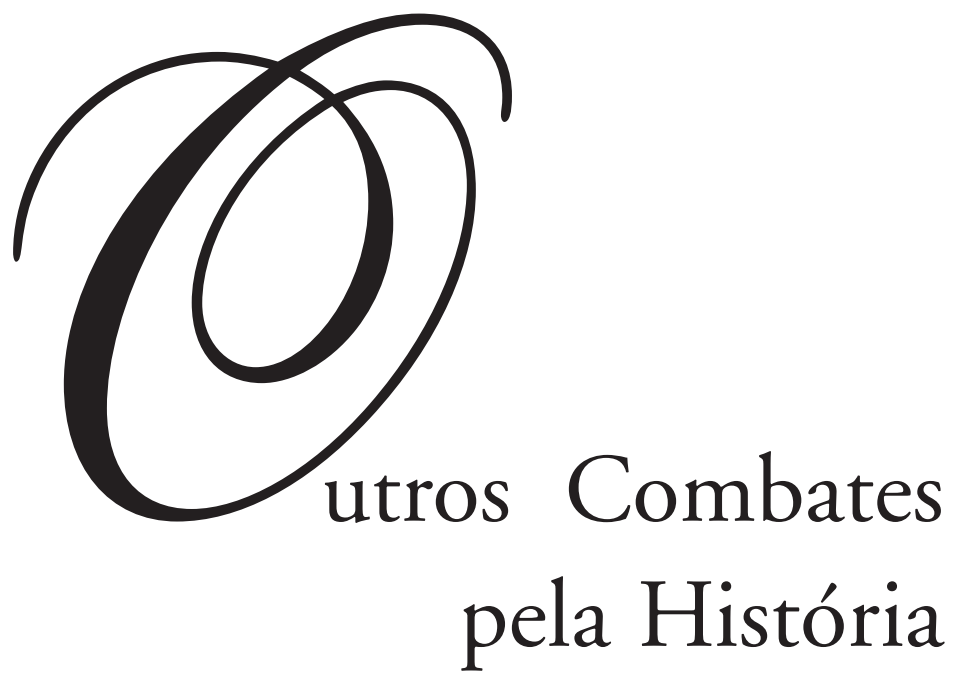

- colmbra 2010 
História e CiênCias 


\section{Augusto Moutinho Borges}

\section{ONTOlogia PRAGMÁtica do AgIR EM S. JoÃo de DEUS}

\section{O estado da arte em S. João de Deus}

Analisando os conceitos inerentes no título, que servem de base para o nosso desenvolvimento temático, directa e indirectamente relacionado com João Cidade, ou melhor dizendo com S. João de Deus, vamos debater um conjunto de ideias sobre a sua vida, a qual está profundamente inter-relacionada com o paradigma humano e a experiência sobre humana, para lidar com os humanos. E entendemos nesta abordagem deontológica, direccionada para o agir em prol do outro como matéria objectiva e elementos para a realização assistencial, num tempo e espaço circunscrito a um território peninsular, só foi possível pela existência de factores específicos. Realçamos a unidade entre os conceitos holísticos de João Cidade, o português, para aquela pessoa, que por sua vez se multiplica indefinidamente por todo um conjunto universal ${ }^{1}$. A verdade é desenvolvida em uníssono por uma variável de culto, não da sua responsabilidade, mas que transposto no semelhante, está impresso no lema proclamado, fazei o bem a vós mesmos dando aos pobres ${ }^{2}$. Desenvolveu o seu agir, voltou-se para o outro onde se identifica para, também, crescer com a humanidade ${ }^{3}$.

O modelo que João Cidade deixou, aos seus companheiros de hábito, é, em nosso entender, um conjunto de valores sem limites, mostrando através de exemplos e práticas reais, o caminho e orientações a seguir mais além. Sem regras, sem normativas, sem um rumo confinado, ao que normalmente interpóe o que obedece ao instituidor, mas convicto nos princípios de bem-fazer, o que hoje é prática corrente nos países ditos civilizados. Se decantarmos os exemplos, as respostas e observações que o Santo nos deixou, concluímos que toda a essência, dos valores preconizados pelos objectivos para com o próximo, constituem, por inerência conceitual, todos os preceitos que hoje é normativo dos juízos de valor.

\footnotetext{
${ }^{1}$ GameIro, Aires, O.H. - «Tempo e originalidade assistencial de S. João de Deus. Koinonía, Filoxenía e Martýrion». Lisboa: Hospitalidade-Rei dos Livros, 1998.

${ }^{2}$ Monteiro, Hernâni - S. João de Deus (no $4 .{ }^{\circ}$ centenário da sua morte). Porto: Faculdade de Medicina do Porto, 1950.

${ }^{3}$ Martinez, José Sanchez - "Kénôsis-Diakonía» en el itinerario espiritual de San Juan de Dios. Madrid: Fundación Juan Ciudad, 1996.
} 
S. João de Deus é a personificação da entrega do ser humano para com a humanidade, numa totalidade abrangente em todos os sectores sociais e sem idades ${ }^{4}$. Na actualidade não estranhamos os exemplos que praticou, mas foi necessário que os tivesse concretizado para, de forma abrangente a toda a cidade granadina, serem desenvolvidos e proclamados ao continente europeu, e por sua vez ao mundo ${ }^{5}$. Mesmo que o homem irrompa pelo universo, há-de levar os exemplos de entrega e prática holística nas astronaves. Sem o saberem irão, tal como no séc. XVII os peninsulares fizeram, transmitir os ensinamentos de João Cidade, ou se quisermos, João de Deus, enraizar novos conceitos assistenciais a todos os que o rodeavam ${ }^{6}$.

Falar deste português, e depois de tantos autores o terem já feito, que podemos adiantar sobre os exemplos que perduraram no tempo até ao presente. Tivemos a oportunidade, conjuntamente com outros investigadores, de reunir a totalidade da bibliografia existente em Portugal sobre o Santo ${ }^{7}$, constatando que muito pouco iríamos acrescentar sobre tudo o que já foi dito. Desde a poesia à prosa, romances, banda desenhada, artigos, livros técnicos e científicos, de tudo se escreveu em torno de S. João de Deus. No entanto e pela componente que temos analisado, sobre a problemática assistencial, é a representação artística aquela que, sem palavras, expressa num nanossegundo, o que a visão humana permite captar ${ }^{8}$.

Aludiremos então à vida e obra de $S$. João de Deus pela imagem. De forma artística, erudita ou popular, esta visão estética permite-nos percorrer toda a panóplia dimensional que os milhares de palavras não conseguem reproduzir, ou fazer-nos recuar no tempo cenográfico do espaço urbano andaluz.

De toda a matéria essencial para a concepção estética utilizada para, e como suporte, analítico relacionado com o agir de $S$. João de Deus, teremos alguma dificuldade em consubstanciar qual a representação que melhor caracteriza o seu amor pelo próximo, ou seja o outro.

Muitos têm sido os motivos captados pelos mestres para definir qual a representação mais fiel ao seu provir ${ }^{9}$. Desde o séc. XVII até ao presente localizamos e

\footnotetext{
${ }^{4}$ Angelini, Fiorenzo - S. João de Deus e S. Camilo de Lélis: Homens e Modelos para a Humanização e Pastoral da Saúde. Lisboa, Cáritas Portuguesa, col. Cáritas, n. ${ }^{\circ}$ 9, 1986.

${ }^{5}$ Brochado, Idalino da Costa (coord.) - São João de Deus, homenagem de Portugal ao seu glorioso filho, 1550-1950. Lisboa: Bertrand, 1950.

${ }^{6}$ Matos, Manuel Cadafaz de - «Para a historiografia de S. João de Deus (novas achegas)». In: Revista

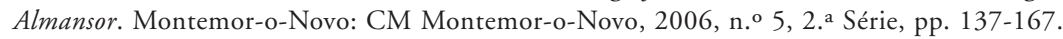

7 GOMES, 2007, p. XXI-LI. GOMES, Josué Pinharanda (coord.) - «A Bibliografia portuguesa relativa a S. João de Deus e às Ordens por ele inspiradas, 1950-2006». In: São João de Deus, homenagem de Portugal ao seu glorioso filho, 1550-1950, fac-símile. Badajoz: Alcalá/OHSJD, 2006, pp. XXI-LI. Vide obra bibliográfica completa.

${ }^{8}$ AZEVEDo, Carlos Moreira - «As origens dos ciclos iconográficos de S. João de Deus». In: 75 anos da Restauração da Provincia Portuguesa da Ordem Hospitaleira de S. João de Deus. Lisboa: Alcalá/OHSJD, 2006, pp. 201-219.

9 Larios Larios, 2006, pp. 139-184. Larios LaRIOS, Juan Miguel, «Iconografia de San Juan de Dios». In: Arte e cultura nell'Ordine Ospedaliero di San Giovanni di Dio. Roma: Cúria Generalizia Ordine Ospedaliero di San Giovanni di Dio, 2006, pp. 139-184.
} 
inventariámos em Portugal, centenas de figurações sobre o Santo ${ }^{10}$. Pela arte, e para tal consideramos todo o vasto conjunto de figuraçôes pictóricas e escultóricas que levantamos em território nacional, podemos percorrer toda a vida de S. João de Deus, analisando todos os seus momentos de profunda dedicação assistencial.

\section{A hagiologia de S. João de Deus}

Desde "O nascimento de S. João de Deus» até ao "Trânsito de S. João de Deus», acompanhamos todos os passos que o guindaram ao estrelato canónico, passando pela beatificação em 1630, não sem antes entrarmos, a fundo, na sua deontologia paradigmática do agir.

Concentremo-nos nas figurações artísticas, pois as criações modulares desenvolvem-se em ciclos iconográficos temáticos, representativos da objectividade assistencial do Homem para com a humanidade. Em primeiro lugar temos as suas biografias ${ }^{11}$, que perpetuaram os ciclos representados com base nos testemunhos do processo de beatificação. Damos como exemplo os que directamente estão relacionados com o tema, onde o desempenho profilático está documentado e resulta na admiração miraculosa da sua mística identidade.

Se as obras a que aludimos são, na sua maioria espanholas ${ }^{12}$, pelo território nacional também se escreveram obras sobre a vida e obra do Santo. Em Portugal o tratado do séc. XVIII S. João de Deus, Pai dos Pobres ${ }^{13}$, é contundente para a sua glorificação. $\mathrm{O}$ interesse que esta obra tem, para a nossa análise, é da sua contemporaneidade com a prática dos centros assistenciais existentes em território nacional, fazendo-se dos hospitais o teatro e palco da vida do Santo, como se estas fossem coetâneos testemunhos do seu agir. Nesta obra, é referenciada a enfermaria do Hospital do Convento de Lisboa e de Montemor, onde podemos analisar a distribuição do centro assistencial, do quotidiano do Santo e das Casas por ele fundadas. Tudo em prol da assistência.

Desde o séc. XVII, a representação iconográfica de S. João de Deus tem uma orientação artística multifacetada. Tanto aparece com a romã na mão, ao jeito de afirmação do vaticínio que o Menino Jesus lhe atirou na borda de duma fonte "João, Granada será a tua cruz», e na outra a cruz patriarcal de fundador de uma Ordem Religiosa, como tendo um livro numa das mãos e a outra em ascética postura, ou segurando,

\footnotetext{
10 Borges, Augusto Moutinho - «S. João de Deus na arte em Portugal». In: Revista Jornadas de História da Medicina da Beira Interior. Castelo Branco, 2007, n. ${ }^{\circ}$ 18, pp. 96-108.

11 Gomes, Josué Pinharanda - 2007, ob. cit.

${ }^{12}$ Gouveia, António de - Vida y Mverte del Bendito P Ivan de Dios, fundador de la ordê de la hospitalidad de los pobres éfermos. Al Exmo. Sr. D. Dvarte, Marquês de Frechilla. D.F. Antonio de Govea-opó. De Cirene visitador Apos. ${ }^{c o}$ en Persia del Consejo de Su Mag. ${ }^{d}$ y Su Predicador por la Corona de Portugal. Madrid: por Thomas Iuiiti, Impressor del Rey, MDCXXIIII, e TRINCHERIA, Manuel - Pasmosa vida, heroycas virtudes, y singulares milagros del Abrahan de la ley de gracia, Patriarca, y fundados de la Sagrada religión Hospitalaria el glorioso San Juan de Dios. Madrid: D. Joachin Ibarra, Impressor de Cámara de S. M., MDCCLXXIII.

13 Correia, Frei Joseph - «S. João de Deus, Pai dos Pobres, Introdução, Transcrição e Índice Remissivo por SALGADO, Abílio José e SALGADO, Anastásia Mestrinho". Lisboa: Multinova, 1997.
} 
pelas mãos, o crucifixo, tal como referem as fontes documentais no momento da sua morte e seu trânsito.

Aliás, o trânsito de S. João de Deus é o embrião artístico que remete o leitor à interpretação do bem morrer, em alusão às obras espirituais em perfeita comunhão com as corporais, tal como prescritas nas obras da misericórdia e seguidas na obra Postilla Religiosa e Arte de Enfermeiro ${ }^{14}$. E é por esse motivo que o Santo se fez representar, na Bandeira da Misericórdia da Guarda, estando ali figurado com um menino aos ombros, aludindo à cenografia do já referido vaticínio ${ }^{15}$. Esta figuração remete-nos para outra causa assistencial de João de Deus: as crianças. Temos alguns exemplos pictóricos sobre o tema em Castelo de Vide, pintura a fresco, na parede da sacristia do antigo Real Hospital Militar, e uma pintura a óleo sobre cobre, proveniente do antigo Real Hospital Militar de Ponte de Lima, para além da figuração, de pintura sobre tela, existente na Misericórdia de Borba.

Analisando estas representações temos de penetrar na imensidão iconoclasta sobre a hagiologia de S. João de Deus. Esta localiza-se em livros e estampa individualizadas, as quais circularam pela Europa, desde o passado, e concretamente do séc. XVI, até ao presente, e serviram de modelo para os mestre e pintores conceberem a representação do carisma joandeino ${ }^{16}$.

\section{Exemplos por séculos na escultura e pintura}

Em Portugal a figuração a que S. João de Deus está intimamente associado, tem origem no séc. XVII, na já referida Bandeira da Santa Casa da Misericórdia da Guarda, em 1608 , e projecta-se até ao presente ${ }^{17}$. A iconoteca hagiológica do Santo é muito vasta, abrangendo aspectos assistenciais, notícias miraculosas e verdadeiros exemplos e lições de vida, as quais, pelo despojamento material em que vivia, continuam a ser referenciadas nas pastorais ecuménicas internacionais gerais e especificamente nas hospitalares, que definem o visado como embrião da nova matriz assistencial. E a verdade é que os seus conceitos sobre a prática a desenvolver estão sempre actualizados ${ }^{18}$.

Vejamos então onde se localizam em Portugal as obras pictóricas e escultóricas. Da inventariação que efectuamos destaco, tanto a nível de significado como da expressão

\footnotetext{
14 Santiago, Fr. Diogo de - Postilla Religiosa e Arte de Enfermeiros. Lisboa: Oficina de Miguel Manescal da Costa, 1741, fac-símile, 2006.

15 Borges, Augusto Moutinho - "Culto a S. João de Deus na Bandeira da Misericórdia da Guarda». In: Revista Cidade Solidária. Lisboa: SCM Lisboa, 2006, pp. 68-73.

16 Cúria Generalizia Ordine Ospedaliero di San Giovanni di Dio, 2006. Cúria Generalizia Ordine Ospedaliero di San Giovanni di Dio (coord.) - "Arte e cultura nell'Ordine Ospedaliero di San Giovanni di Dio». Roma: Cúria Generalizia Ordine Ospedaliero di San Giovanni di Dio, 2006.

17 Borges, Augusto Moutinho - Os Reais Hospitais Militares em Portugal administrados e fundados pelos Irmãos Hospitaleiros de S. João de Deus, 1640-1834. Lisboa: Faculdade de Ciências Médicas de Lisboa-UNL, 2007 (Tese de Doutoramento).

18 ANGELINI, Fiorenzo - ob. cit., 1987.
} 
conceitual do objecto como arte ${ }^{19}$, o silhar azulejar do Santo, séc. XVIII, c. 1740, quando estava internado no Real Hospital de Granada. A cenografia remete-nos a olhar o português louco a ser chicoteado, pois era este o tratamento dado aos doentes do foro psiquiátrico, perante observação dos médicos e enfermeiros. Nós somos parte integrante desta cenografia, como impávidos assistentes testemunhando o espectáculo, tal como todos os que lá se encontram.

Vamos, através de um exemplo por século, um para a escultura e outro para a pintura, referenciar aqueles que, para nós, constituem os modelos imagéticos dos ciclos artísticos assistenciais em Portugal, considerando-os testemunhos que, para além de glorificarem $S$. João de Deus, o colocam de forma interactiva, lado a lado com os seus interlocutores, tanto no passado como no presente.

A bibliografia que anexamos no final serve, para os mais interessados na temática, para novos ciclos de análise.

\section{Século XVII}

Escultura. S. João de Deus patriarca. Madeira estofada e policromada.

Localização: Capela da Casa de Saúde do Telhal. Estava no altar-mor da igreja do Convento-Hospital de S. João de Deus, em Lisboa, e actualmente em altar lateral da referida Capela.

Observações: Faz parte de um conjunto de S. João de Deus e S. Rafael.

Bibliografia específica: BORGES, Augusto Moutinho - Os Reais Hospitais Militares em Portugal administrados e fundados pelos Irmãos Hospitaleiros de S. João de Deus, 1640-1834. Lisboa: Faculdade de Ciências Médicas de Lisboa-UNL, 2007 (Tese de Doutoramento).

Pintura. S. João de Deus a receber o menino Jesus de N. a Sra de Guadalupe para o vestir. Técnica a fresco.

Localização: Castelo de Vide, na Estrada do Marvão. Na sacristia da capela do extinto Real Hospital Militar de S. João de Deus. Propriedade privada.

Observações: Julgamos que este painel seria o primeiro de uma série, que por motivos que desconhecemos não foram concluídos.

Bibliografia específica: BORGES, Augusto Moutinho - «Iconografia de S. João de Deus no Alentejo, Séculos XVII-XX». In: Revista Almansor. Montemor-o-Novo: CM Montemor-o-Novo, 2007, n. o 6, pp. 323-375.

\section{Século XVIII}

Escultura. S. João de Deus a transportar um louco. Madeira estofada e policromada.

Localização: Castelo Branco. Museu da Santa Casa da Misericórdia.

Observações: Faz parte de um conjunto de S. João de Deus e da Rainha Santa Isabel de Portugal.

Bibliografia específica: FONSECA, Jorge - Catálogo de exposição de Escultura e pintura sobre S. João de Deus. Montemor-o-Novo: CM Montemor-o-Novo, 1995.

19 Sobre a representação do lava-pés vide GAMEIRO, Aires, O.H., e BorgES, Augusto Moutinho "Alegorias da Fé: S. João de Deus». In: Catálogo O azulejo nas Caldas da Rainha: Memória, Cerâmica, Brilho, Expressão e Narrativa Alegórica. Caldas da Rainha: Museu do Hospital e das Caldas, 2007, pp. 7-11. 
Pintura. S. João de Deus internado no Hospital Real de Granada a receber o tratamento dado aos loucos. Azulejo.

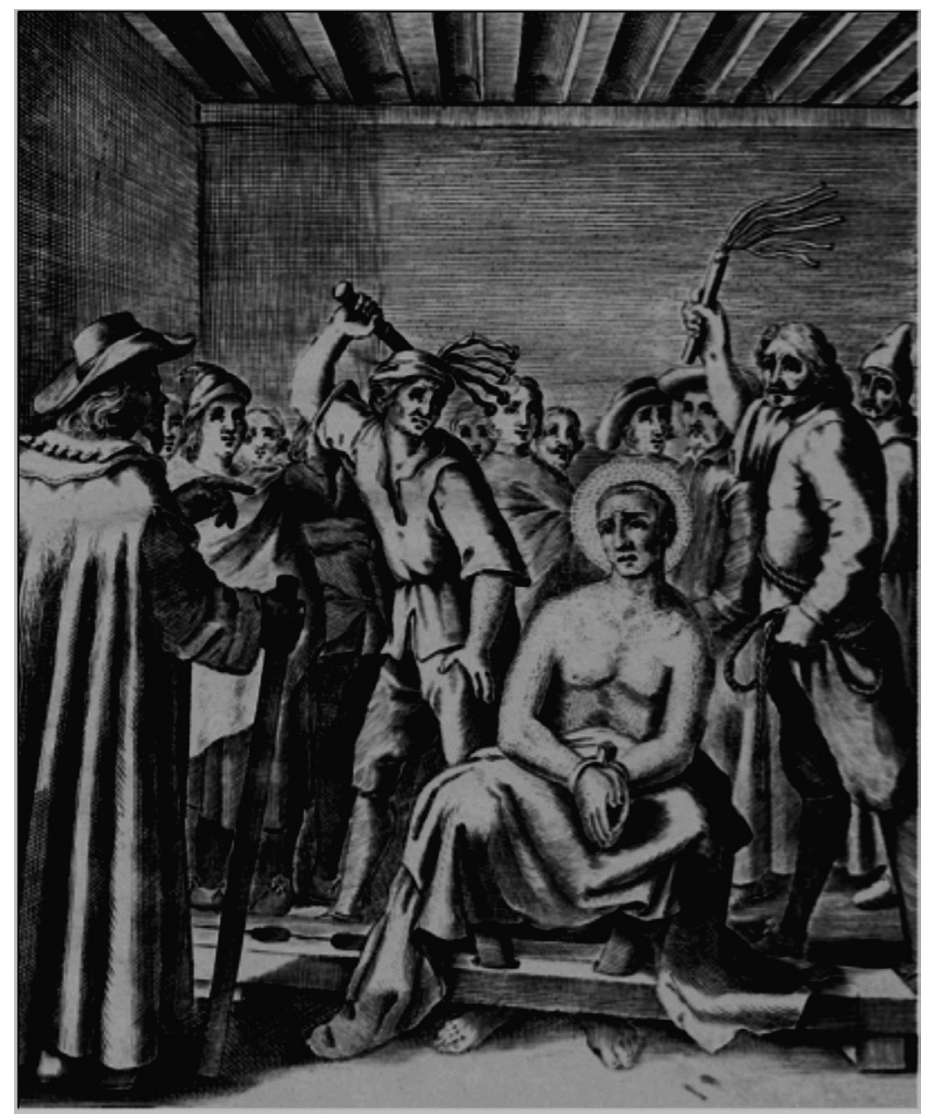

TRINCHERA, 1773, p. 104

Localização: Lisboa, no átrio do Convento-Hospital de S. João de Deus, Rua das Janelas Verdes à Pampulha. Actual comando da Brigada de Trânsito da Guarda Nacional Republicana.

Observaçôes: Faz parte de um conjunto de sete painéis de azulejo com as figurações do Nascimento de S. João de Deus, S. João de Deus pastor em Oropesa, S. João de Deu cain do cavalo e foi ajudado por N. ${ }^{a}$ Sr. ${ }^{2}$, S. João de Deus soldado alimentado pelo maravilhoso, S. João de Deus ouve o sermão de S. João de Avila, S. João de Deus internado no Hospital Real de Granada a receber o tratamento dado aos loucos, $S$. João de Deus acusado de bruxaria por acender uma fogueira quando chovia.

Bibliografia específica: BORgES, Augusto Moutinho - Os Reais Hospitais Militares em Portugal administrados e fundados pelos Irmãos Hospitaleiros de S. João de Deus, 1640-1834. Lisboa: Faculdade de Ciências Médicas de Lisboa-UNL, 2007 (Tese de Doutoramento), Brochado, Idalino da Costa (coord.), São João de Deus, homenagem de Portugal ao seu glorioso filho, 1550-1950. Lisboa: Bertrand, 1950, pp. 223-231. SILVA, Manuel Ferreira da - «S. João de Deus no contexto geral da história». In: Hospitalidade com S. João de Deus no coração da história. Lisboa: Hospitalidade-Rei dos Livros, 1994, pp. 77-115. 


\section{Século XIX}

Escultura. Não temos referências.

Pintura. S. João de Deus na enfermaria com um doente, ajudado por S. Rafael. Azulejo.

Localização: Lisboa. Na actualidade está na escadaria secundária do Hospital de S. José.

Observações: O registo encontrava-se na antiga enfermaria S. João de Deus, que depois foi adaptada a biblioteca. Com obras de remodelação foi retirado e aplicado no local onde hoje se encontra.

Bibliografia específica: Borges, Augusto Moutinho - Os Reais Hospitais Militares em Portugal administrados e fundados pelos Irmãos Hospitaleiros de S. João de Deus, 1640-1834. Lisboa: Faculdade de Ciências Médicas de Lisboa-UNL, 2007 (Tese de Doutoramento), PINA, Madalena Esperança - Traços da Medicina na azulejaria de Lisboa. Lisboa: Faculdade de Ciências Médicas de Lisboa-UNL, 2007 (Tese de Doutoramento), Veloso, António Barros e AlMASQUÉ, Isabel - Hospitais Civis: História e Azulejos. Lisboa: Inapa, 1996.

\section{Século XX}

Escultura. S. João de Deus com o doente ao colo. Madeira estofada e policromada.

Localização: Lisboa. Sede da Ordem Hospitaleira de S. João de Deus.

Autoria: Mestre José Ferreira Thedim, 1928.

Observações: Foi Prémio Internacional de Escultura de arte sacra.

Bibliografia específica: TEDIM, José Manuel - "As estátuas de S. João de Deus da responsabilidade da oficina do Comendador José Ferreira Thedim, o escultor da imagem de S. João de Deus, da Ordem Hospitaleira de S. João de Deus». In: 75 anos da Restauração da Província Portuguesa da Ordem Hospitaleira de S. João de Deus. Lisboa: Alcalá-OHSJD, 2006, pp. 222-228.

Pintura. Vida e Obra de S. João de Deus. Técnica a fresco.

Localização: Lisboa. Igreja S. João de Deus.

Autoria: Mestre Domingos Rebelo, 1952.

Observaçōes: Tríptico.

Bibliografia específica: BORGES, Augusto Moutinho - "As pinturas do Mestre Domingos Rebelo no Alentejo». In: Revista Almansor. Montemor-o-Novo: CM Montemor-o-Novo, 2008, n. ${ }^{\circ}$ 7, pp. 212-231.

\section{Conclusão}

Podemos, pela arte, analisar as diversas facetas assistenciais que caracterizam o agir universal de $S$. João de Deus.

A sua iconografia está difundida pelo mundo centrada, essencialmente, no tema da prática assistencial, quer na globalidade, quer especificamente no cuidado ao doente do foro psiquiátrico.

Do levantamento e inventariação que fizemos em Portugal, apresentamos alguns exemplos que, julgamos, representam a acção paradigmática universal do agir em S. João de Deus. 
Série

Documentos

Imprensa da Universidade de Coimbra

Coimbra University Press

2010

- U

C • 